\title{
Toxocariasis in the Americas: Burden and Disease Control
}

\author{
Adrián Bolivar-Mejia • Camila Alarcón-Olave • \\ Lauren S. Calvo-Betancourt • Alberto Paniz-Mondolfi • \\ Olinda Delgado • Alfonso J. Rodriguez-Morales
}

Published online: 16 January 2014

(C) Springer International Publishing AG 2014

\begin{abstract}
Human toxocariasis is a zoonotic parasitic disease that represents extensive morbidity in many countries. Caused by Toxocara canis and Toxocara cati, the clinical spectrum of this helminthiasis can be extended from asymptomatic forms up to life-threatening syndromes, such as the visceral larva migrans. Its epidemiology and burden is not clear; many times it is not diagnosed and, in most countries, it is not a notifiable disease. Some recent reviews have shown a large range of variability in terms of reported seroprevalence by countries. In this review, we summarized information regarding human
\end{abstract}

A. Bolivar-Mejia · C. Alarcón-Olave · L. S. Calvo-Betancourt Faculty of Health, Universidad Industrial de Santander,

Bucaramanga, Santander, Colombia

\section{A. Paniz-Mondolfi}

Department of Pathology and Laboratory Medicine, St.

Luke's-Roosevelt Hospital Center, St. Luke's Division, New York, NY, USA

\author{
A. Paniz-Mondolfi \\ Laboratoryof Biochemistry, Instituto de Biomedicina, UCV/ \\ MPPSDS/IVSS, Caracas, DC, Venezuela
}

O. Delgado · A. J. Rodriguez-Morales

Immunoparasitology Section, Instituto de Medicina Tropical "Felix

Pifano", Faculty of Medicine, Universidad Central de Venezuela,

Caracas, DC, Venezuela

\section{A. J. Rodriguez-Morales ( $\square$ )}

AIDS and Other Infectious Diseases Research Group, Faculty of Health Sciences, Universidad Tecnológica de Pereira, Pereira,

Risaralda, Colombia

e-mail: arodriguezm@utp.edu.co

\section{A. J. Rodriguez-Morales}

International Society for Chemotherapy (ISC) Working Group on

Zoonoses Committee, Aberdeen, Scotland, United Kingdom.

Comitee on Zoonoses and Haemorrhagic Fevers,

AsociaciónColombiana de Infectología (ACIN), Bogotá, DC,

Colombia toxocariasis burden of disease and control efforts in the region of the Americas.

Keywords Toxocara $\cdot$ Toxocara canis $\cdot$ Toxocara cati . Toxocariasis · Epidemiology $\cdot$ Zoonoses $\cdot$ Americas · Burden · Diagnosis $\cdot$ Control $\cdot$ Prevention $\cdot$ Public Health

\section{Introduction}

Toxocariasis is known as a worldwide distributed zoonosis, caused by the infection in humans of Toxocara canis and Toxocara cati, two ascarid parasites which are found in their adult forms in the small intestines of dogs and cats [1•,2]. Although most studies have focused their attention on the infection due to $T$. canis, human infection acquired from cats is also frequent in many settings. As a result, toxocariasis, which could be considered a neglected parasitic infection, is even more understudied in the case of the cat ascarid infection in humans. The infection occurs in humans by the accidental ingestion of larval eggs that stay in the intestine where they can cause little and self-limiting inflammatory reactions, severe systemic infections, or even death $[1 \cdot 2,3]$.

Once a human becomes infected, this tends to become a chronic process with a wide spectrum of clinical manifestations, ranging from asymptomatic courses, to the characteristic forms of clinical presentations such as: visceral larva migrans syndrome (VLM) and ocular larva migrans syndrome $(\mathrm{OLM})[1 \bullet 4]$. VLM may affect several organs such as the liver, manifesting as hepatitis or hepatomegalia; the lungs, in which cough or asthmatic crises can occur; and the heart, where it may produce myocarditis or congestive heart failure. Other organs, such as the skin, central nervous system, and kidneys, may also become affected. Such presentation is associated with relevant number of Toxocara larvae and is usually seen in children less than 5 years $[1 \bullet, 4]$. OLM occurs 
usually in people over 5 years. Evidence suggests that this form of human toxocariasis tends to occur in the absence of systemic and visceral involvement. The principal manifestation that the larva migrans causes when invading the eye is retinal damage $[1 \cdot 5]$.

Toxocariasis has a worldwide distribution, being considered endemic in most of America, Africa and Asia [5•]. This zoonosis is well related to the human pattern to live near to dogs and cats, and the inadequate management of the animals feces [1•]. The seroprevalence in Latin America ranges from 1.8 up to $66.6 \%$ (Fig. 1). It is estimated that the prevalence rates of Toxocara canis in dogs can vary between 0 and $99.4 \%[1 \bullet, 4]$. Infection rate is usually higher in younger animals. In general, the seroprevalence rates vary from country to country. According to some reports, these could be: $27 \%$ in Bolivia, $8.7 \%$ to $38.8 \%$ in Brazil, $2.2 \%$ in Chile, $47.5 \%$ in Colombia, $5.2 \%$ in Cuba, $6.5 \%$ in Puerto Rico, $34.9 \%$ to $66.6 \%$ in Venezuela, $27.2 \%$ to $62.3 \%$ in Trinidad, $7.33 \%$ to $32.4 \%$ in Peru, $30 \%$ in Ecuador and $10.6 \%$ to $36.9 \%$ in Argentina [2, 5•].

The transmission of larval eggs is always orally and there are two ways of acquiring the infection: direct oral transmission, which occurs in people with geophagy (the habit of eating dirt), commonly seen in psychiatric or pediatric patients, and the indirect oral transmission that occurs by consuming contaminated food with the juvenile larval forms $[4,6]$.

Like many other parasitic diseases, toxocariasis is much more common in developing countries, especially in rural areas, where the estimated seroprevalence is $37 \%$, compared with urban areas for which it is about $2-14 \%[1 \bullet, 7,8]$. However, accurate statistics in Latin America are poorly known because it is not a disease under epidemiological surveillance. So, in this review, we summarize the information regard the epidemiological burden of this zoonotic disease in the Americas and discuss its impact on regional public health.

\section{Toxocariasis in the United States}

In the United States (US), a decrease in the mortality rate resulting from infectious diseases has occurred over time, even more from tropical and parasitic diseases. However, among the poorest people living in the US, there is a group of serious parasitic and bacterial disease including toxocariasis, cysticercosis and Chagas disease. Toxocariasis is a disease belonging to the group known as the "neglected infections of poverty", because it is a disease that has been forgotten by the US public health community and it promotes poverty through its impact on child health and development $[9,10]$.

Toxocariasis is a very common human parasitic worm infection in the US; , it is closely related to poverty status in the US, which is higher in non-metropolitan areas, especially in the south and among non-Hispanic blacks and Native Americans, as has been reported previously [9]. Children are particularly prone to infection because they are exposed to the eggs in sandboxes and playgrounds contaminated with dog and cat feces [11•]. The prevalence rate of toxocariasis, which is based on serologic

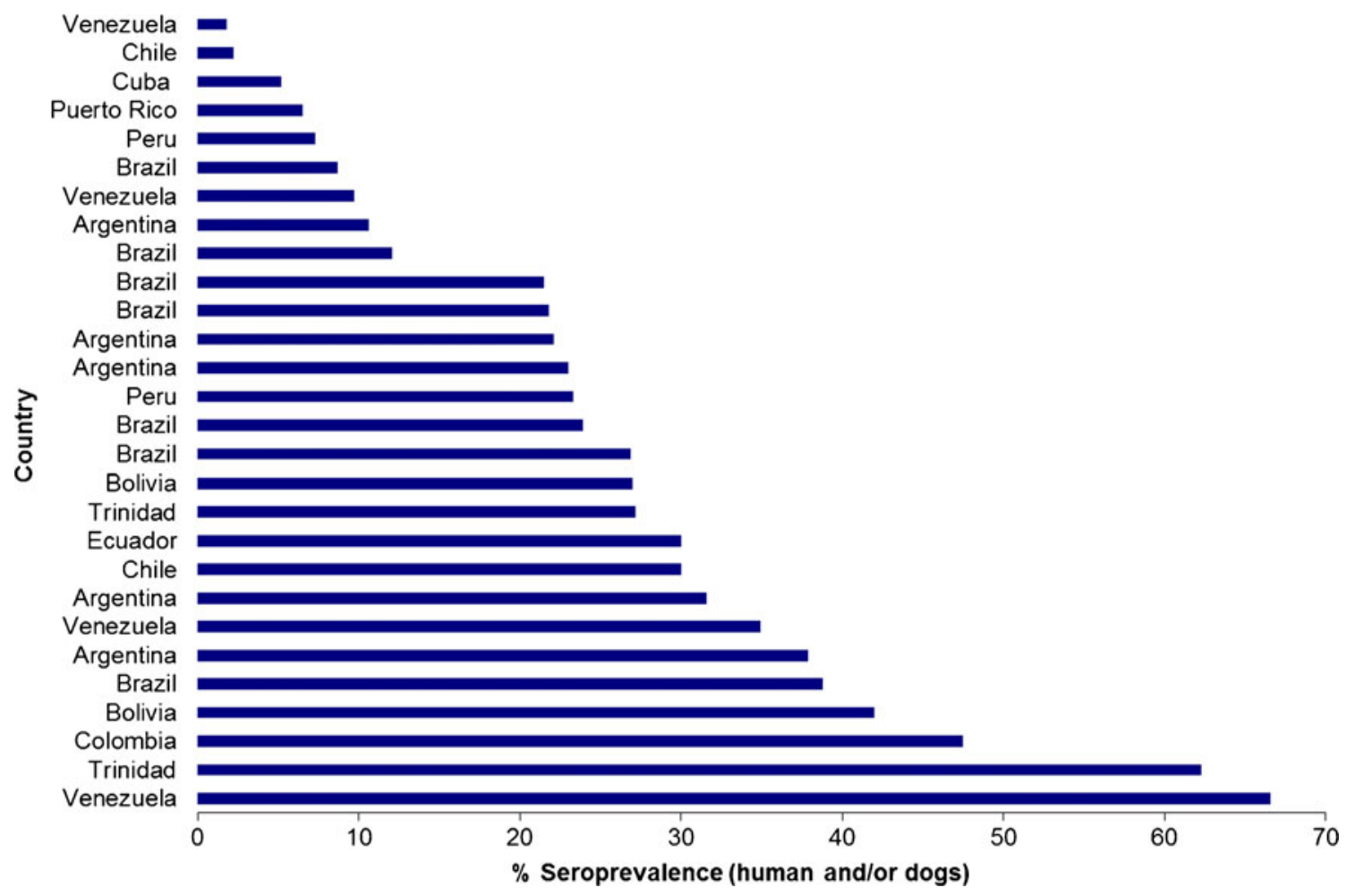

Fig. 1 Reported Seroprevalences of Human Toxocariasis in Latin American countries 
studies that measure antibodies to T. canis antigens, among inner city blacks living in Connecticut cities was found to be $10 \%$ and even higher among inner city Hispanics [12]. The prevalence among socioeconomically disadvantaged blacks in the American South was as high as $30 \%$ between 1971 and 1973 [13]; however, it was recently estimated that approximately $21 \%$ of blacks are seropositive [14]. So, based on the estimate that 13.3 million impoverished blacks live in America [15], with prevalence estimates between $10 \%$ and $21 \%$, as many as 1.3 million to 2.8 million individuals may be exposed or infected, making this disease one of the most common infections among any underrepresented minority group [9].

An overall prevalence of $13.9 \%$ positive for antibodies to Toxocara was determined by the Third National Health and Nutrition Examination Survey (NHANES III) in 2008; suggesting that tens of millions of Americans are infected with Toxocara [11•]. This prevalence is almost two to three times the prevalence reported more than 20 years ago by the NHANES I [16].

Toxocariasis had been linked to childhood asthma as it may manifest with wheezing, pulmonary infiltrates and eosinophilia, features that are also the hallmark of childhood asthma. Similarly, some of the central nervous system features of toxocariasis have been implicated as a cause of occult seizures, mental retardation, and developmental delays [16]. Knowing this association, human toxocariasis may represent a health disparity, possibly associated with the high frequency of asthma and developmental delays noted among African Americans and some Hispanic groups living in poverty [17-20]. Another important association has been described between Toxocara and Toxoplasmosis; however, further research is needed to establish the impact of this association in the US population[21].

Ocular and visceral larva migrans, although uncommon diseases, are an important cause of morbidity mainly in young children. Ocular toxocariasis incidence has previously been estimated at just one per 10,000 annually [16]; however, the incidence of larva migrans had not yet been determined [23]. Ocular toxocariasis causes debilitating ophthalmologic disease, including blindness; it affects people 5 to 10 years old, but up to $20 \%$ of cases occur in people over the age of 16 years. In a web-based survey conducted between September 2009 to September 2010, ophthalmologists belonging to the American Uveitis Society (AUS), the American Society of Retina Specialists (ASRS), or the American Association for Pediatric Ophthalmology and Strabismus (AAPOS) reported a total of 68 newly diagnosed ocular toxocariasis patients from 23 states, the District of Columbia, and Puerto Rico; $57 \%$ of ocular toxocariasis patients lived in the South, median age was 8.5 years and $64 \%$ owned a pet. The main symptom observed was vision loss in $83 \%$ of the cases, $68 \%$ of whom had permanent vision loss [24]. A previous multicenter survey performed in 1987 in Alabama estimated a statewide prevalence of one per 1,000 persons [25].
With all these considerations in mind, it can be correctly assured that toxocariasis is an important preventable and treatable disease affecting millions of Americans and causing a great health and socioeconomic impact, so it is important to establish and carry on health policies in order to diminish the burden caused by this disease among the American population, especially those living in poverty conditions. One identified obstacle for the control and elimination of this disease is the absence of reliable population-based estimates of prevalence and disease burden data about this condition [9, 26]; however, there are several tools for the control of this disease based on controlling Toxocara infection in dogs. This includes routine deworming, avoiding human exposure to possible source of infection by immediate disposal of pet feces, good hygiene practices, improvements in environmental sanitation, and case detection and treatment with albendazole. Implementing these tools will help prevent infection and decrease morbidity associated with Toxocara [26].

\section{Toxocariasis in Canada}

In Canada, data about prevalence of Toxocara canis infection are limited; in 1988, in a study conducted among children aged less than 1 year to 15 years, the overall prevalence of Toxocara canis antibodies was 17.0 , identifying a greater prevalence of antibody in rural areas than in urban children and showing an association between an age of greater than 6 years and dogs in the household with an increased risk of infection, but only among rural children [27].

It is estimated that about $34.0 \%$ of dogs are infected with Toxocara canis, having an incidence of $50 \%$ in dogs less than 3 years old and $41.8 \%$ in those 3 to 6 years old; only $10 \%$ of older dogs are infected. A presence of Toxocara eggs was found in 14 public parks examined between October and November 1976; however, further research needs to be done in order to determine the actual burden of Toxocara canis infection in Canadian soil and among the population [28].

\section{Toxocariasis in Mexico}

The absence of reliable mortality data and no national disease burden estimates in DALYs for toxocariasis in Mexico has necessitated estimates of its burden based on five crosssectional studies conducted in children of selected Mexican cities and special groups at risk [22, 29]. In 2008, the seroprevalence of Toxocara canis larva migrans in children aged 1 - 12 years from the urban area of Mexicali was $10.6 \%$, which was similar to the previously reported prevalence of $7.5 \%$ [30] in Mexico City children of similar ages, but lower than the prevalence reported in children from other Latin American countries. In Argentina the seroprevalence found 
for larva migrans due to Toxocara canis was $37.9 \%$, similar to the one found in Brazilian and Bolivian children of $38.8 \%$ and $34.6 \%$, respectively. However, $81 \%$ of seropositivity has been reported in the few Colombian studies that have been published [31]. This low prevalence found in Mexicali can possibly be explained by the hot and dry weather conditions that may not allow the development of the infective stage of the Toxocara canis eggs.

A more recent study conducted in Ecatepec of Morelos (a city in the metropolitan area of Mexico City) showed a prevalence of Toxocara canis in children between $2-16$ years old of $22.22 \%$ with a greater prevalence in males than females ( $28.84 \%$ and $16.07 \%$, respectively), that was not found by the previously available information [32].

In humans, the seroprevalence of larva migrans due to Toxocara canis has been associated with the prevalence of Toxocara canis in dogs, geography, playing in parks and contact with objects contaminated with infected dogs feces. Preliminary studies have shown a high prevalence of Toxocara canis eggs in soil sampled from parks and playgrounds of the Mexicali area $(62.5 \%)$ as well as a high prevalence in dogs $(56.1 \%$; $95 \%$ CI $49.6-62.5 \%)$. These findings suggest a high existing risk of infection with larva migrans due to Toxocara canis within the local population of Mexicali; however, the only study conducted in this city showed a low seroprevalence compared to one that should be expected considering the high prevalence of soil contamination mentioned before [31].

Regarding other risk factors, two previous studies, conducted in 1997 and 2008, found no statistically significant differences between gender and Toxocara canis seroprevalence, suggesting that boys and girls are at the same risk for Toxocara canis infection [30, 31]; however, a recent study done in a district of Mexico city found that boys were more prone to be infected with Toxocara canis than girls with a seroprevalence of $28.84 \%$ and $16.07 \%$, respectively, and that seroprevalence tends to be lower in the youngest children [33].

Dog ownership is considered a risk factor for the presence of Toxocara canis seropositivity; however, only one study in Mexico found a significant association between owning dogs younger than 1 year of age and the presence of Toxocara canis seropositivity, possibly because the main mechanism of infection in dogs is transplacental and by breastfeeding, so the prevalence of infection in these dogs is higher [33].

Malnutrition/low weight, not washing hands before meals, onicophagia and use of public parks may also be epidemiologically important for presence of Toxocara canis. The prevalence of malnutrition among children less than 5 years old has been decreasing over the years from $10.8 \%$ in 1988 to $2.8 \%$ in 2012, affecting just 299,600 Mexican children, so it would be expected that the contribution of this risk factor to the burden of Toxocara canis may not be significant $[34,35]$.
In relation to special groups at risk of Toxocara canis infection, waste pickers were identified as a population at risk of infection with a seroprevalence of anti-Toxocara IgG antibodies significantly higher than in control subjects (13\% vs. $1 \%$ ) [36]; also, psychiatric in-patients were found to have significantly higher seroprevalence of anti-Toxocara IgG antibodies than controls, suggesting that special attention should be paid to these groups at a higher risk (4.7\% vs. $1.1 \%$ ) [36].

There are no studies done in rural areas of Mexico, where higher rates of infection are expected; neither has the prevalence of ocular larva migrans syndrome due to Toxocara canis been determined, so further studies need to be done to determine more precisely the burden of this disease among the Mexican population.

\section{Costa Rica}

In Costa Rica there are no studies about Toxocara canis infection in humans; however, the presence of Toxocara canis eggs in the soils and playgrounds has been widely described as it constitutes the main source of human infection and geophagia is an important epidemiological factor in visceral larva migrans. A study done in 1986 in Costa Rica evaluated the presence of Toxocara eggs in the soil of 10 parks and playgrounds and 64 particular houses finding eggs of Toxocara canis in the soil of 11 houses (17.2\%) while no eggs were found in the soil from parks and playgrounds. Even though there are no data about prevalence of Toxocara canis infection in humans, having proved the presence of contamination in soil suggests that there is a potential risk of human infection, mainly in the areas nearby the houses where contamination was found, so an important incidence of visceral larva migrans in children could be expected [37].

\section{Other Countries in Central America}

The information about Toxocara canis prevalence in Central American countries is limited. Studies need to be done in Guatemala, Belize, Honduras, El Salvador, Nicaragua and Panama in order to determine the burden of Toxocara canis infection in these countries [29].

\section{Toxocariasis in Brazil}

In Brazil, many studies have been done to determine the seroprevalence of toxocariasis in different population groups, consisting mainly of children, given the concern of the frequency of the infection in this age group. The different reports indicate seroprevalence rates ranging from $2.8 \%$ to $54.8 \%$, identifying associated risk factors with the presence of 
antibodies anti-Toxocara, in which stands the classicallyknown frequent contact with contaminated soils, interaction with dogs, bad hygiene habits, and in association with the last factor, socioeconomic conditions [38-46].

Thus, a study conducted in the city of Brasilia (the capital of the country) which wanted to assess the differences between toxocariasis seroprevalence among children of high and low strata, found that the prevalence of seropositivity in the last group was seven times higher than a group of upper-class children (21.8\% vs. $3 \%)$. It was also noted that having dogs as pets represented a higher risk for lower-class children compared to those of higher class, due to a better management of pet feces, use of pesticides and the best education on hygiene habits [46].

\section{Toxocariasis in Argentina}

In Argentina, although there are several studies on the subject, the exact prevalence of toxocariasis is unknown because it is not a notifiable disease, so it is more difficult to have the proper knowledge of the epidemiology and burden in public health that generates over the country $[8,47]$.

The infection has been studied and described mostly in big cities, where it has been related to the bad habits of the population regarding the management of their pets' feces $[48,49]$. In relation to the above, it is considered that the risk of infection by T. canis, is greater in the home environment, taking into account aspects such as soil, climate and health of pets [50].

In an epidemiological study conducted in Patagonia, a seroprevalence of $31.6 \%$ was found, and the age group between 2 and 10 years was the most affected (42.1\%) [51]. These observations correlate with the findings of Radman et al in their study of 156 patients from the city of La Plata, in which 38 of the 61 patients with positive ELISA were under 15 years [52]. However, in most studies, there has been no significant difference in age and the relationship with positive T. canis seroprevalence [7]. The same was demonstrated in a study in General Mansilla, a rural town located $96 \mathrm{~km}$ from Buenos Aires, where the frequency of toxocariasis was $23 \%$ (23/100), with 17 people under 14 years and six people over this age; however, the difference was not significant [53, 54].

Finally, regarding the symptomatology, according to Lopez Ma et al, in 122 children under 14 years with positive ELISA, $75 \%$ were asymptomatic, and ophthalmologic symptoms were the most common (10\%) [49].

\section{Toxocariasis in Peru}

The estimated frequency in Peru varies from $7.8 \%$ to $32.4 \%$ in the rural areas [55]. But, as in most of the countries in Latin America, the real frequency of Toxocara infection is unknown. However, there are several studies in different population groups that provide a guide for the actual frequency of the infection, including some unpublished studies in poor areas of the capital city, Lima.

A study in the Morrope district, Lambayeque, in a population of 182 school children, a seroprevalence of $32.4 \%$ was shown, with no significant differences between genders. Also reported in this study, was reported a significant association between the use of public playgrounds by children and a seropositive ELISA test. Also, the presence of geophagia was statistically significant. These findings correlate with the known risk factors for Toxocara infection such as: contact with contaminated soil, low socioeconomic conditions and poor hygienic habits. In descending order, the most frequent symptoms were: respiratory signs $(77.96 \%)$, ocular signs $(61.02 \%)$, hepatic compromise $(38.98 \%)$, abdominal pain $(30.51 \%)$ and cutaneous signs $(27.12 \%)$ [2].

In another study, the presence of Toxocara eggs in the soil of public areas in urban areas of Lima was determined. Collected samples came from ten urban parks, of which eight were contaminated with Toxocara eggs. A high frequency of contamination was found in public parks that where used by children as playgrounds. This finding correlates with that observed in other Latin American countries, where the use of contaminated soil areas by children is associated with an increased frequency of infection in this age group $[1,56]$.

\section{Toxocariasis in Venezuela}

Studies in Venezuela began very shortly after toxocariasis was described by Beaver et al in 1952 [57], with clinical reports in 1968 by Latuff \& Cardozo [58]. The first studies in the country found up to $66.6 \%$ seroprevalence in children 2 7 years old of Caracas [59]. In Ameridians from the Venezuelan Amazon region, a seroprevalence of $34.9 \%$ was reported in 1988 [60]. Most studies in the country have been limited to short case series or even case reports.

\section{Conclusion}

National surveys on toxocariasis seroprevalence such as those reported in the US, should be performed in other countries across the region of the Americas, where some limited studies have demonstrated the importance of this parasitic disease, showing rates up to $65 \%$. Unfortunately, in many countries, toxocariasis is neglected [61•] from a public health perspective. Furthermore, controlling the burden of disease of this complex zoonosis is complicated by the existence of wild definitive and paratenic hosts [62••]. Increasing human and dog population size, population dynamics, and climate change could be all factors that may increase the burden of this 
zoonosis in a near future [62••]. We thus hope that increased attention to this highly neglected disease is given to introduce interventions for controlling, and hopefully eliminating, this parasitic infection in the Americas.

Acknowledgement Part of this manuscript was presented in part as Plenary Lecture by A. J. Rodriguez-Morales, at the XXI Latin American Congress of Parasitology (XXI FLAP 2013), Guayaquil, Ecuador, 6-9 October 2013

\section{Compliance with Ethics Guidelines}

Conflict of Interest Adrián Bolivar-Mejia, Camila Alarcón-Olave, Lauren S. Calvo-Betancourt, Alberto Paniz-Mondolfi, Olinda Delgado, and Alfonso J. Rodriguez-Morales declare that they have no conflict of interest

Human and Animal Rights and Informed Consent This article does not contain any studies with human or animal subjects performed by any of the authors.

\section{References}

Papers of particular interest, published recently, have been highlighted as:

- Of importance

•. Of major importance

1. Bolivar-Mejia A, Rodriguez-Morales A, Paniz A, Delgado O. Manifestaciones cardiovasculares de la toxocariasis humana. Arch CardiolMex. 2013;83:120-9. This is the first review on the cardiovascular manifestations of toxocariasis published.

2. Roldán WH, Cavero YA, Espinoza YA, Jiménez S, Gutiérrez CA. Human toxocariasis: a seroepidemiological survey in the Amazonian city of Yurimaguas, Peru. Rev Inst Med Trop Sao Paulo. 2010;52:37-42.

3. Roldan WH, Espinoza YA, Huapaya PE, et al. Diagnostico de la toxocarosis humana. Rev Peru Med Exp Salud Publica. 2010;27: 613-20.

4. Archelli S, Kozubsky L. Toxocara y toxocariasis. Acta Bioquím Clín Latinoam. 2008;42:379-84.

5. Delgado O, Rodriguez-Morales AJ. Aspectos clínicoepidemiológicos de la toxocariasis: una enfermedad desatendida en Venezuela y América Latina. Bol Mal SaludAmb. 2009;49:133. This is a very comprehensive review on toxocariasis.

6. Fonrouge RD, GuardisM Del V, Radman NE, Archelli SM. Contaminación de suelos con huevos de Toxocaraspen plazas y parquespúblicos de la Ciudad de La Plata, Bs As, Argentina. BolChilParasitol. 2000;55:83-5.

7. Won KY, Kruszon-Moran D, Schantz PM, et al. National seroprevalence and risk factors for zoonotic Toxocaraspp. infection. Am J Trop Med Hyg. 2008;79:552-7.

8. Alonso JM, Bojanich MV, Chamorro M. Gorodner JO: Toxocaraseroprevalence in children from a subtropical city in Argentina. Rev Inst Med Trop Sao Paulo. 2000;42:235-7.

9. Hotez PJ. Neglected diseases and poverty in "The Other America": The greatest health disparity in the United States? PLoSNegl Trop Dis. 2007;1:e159.

10. Hotez PJ, Ferris MT. The antipoverty vaccines. Vaccine. 2006;24: 5787-99.
11. Hotez PJ, Wilkins PP. Toxocariasis: America's Most Common Neglected Infection of Poverty and a Helminthiasis of Global Importance? PLoSNegl Trop Dis. 2009;3:e400. Important editorial calling for reflexion about the relevance of toxocariasis in USA.

12. Sharghi N, Schantz P, Caramico L, et al. Environmental exposure to toxocara as a possible risk factor for asthema: A clinic-based casecontrol study. Clin Infect Dis. 2001;32:E111-6.

13. Herrmann N, Glickman LT, Schantz PM, Weston MG. Domanski LM:Seroprevalence of zoonotic toxocariasis in the United States: 1971-1973. Am J Epidemiol. 1985;122:890-6.

14. Won K, Kruzon-Moran D, Schantz PM, Jones JL. National seroprevalence and risk factors for Toxocara spp. infection. Am J Trop Med Hyg. 2007;77:68.

15. Murray CJL, Kulkarni S, Ezzati M. Eight Americas. New perspectives on U.S. health disparities. Am J Prev Med. 2005;29:4-10.

16. Sharghi N, Schantz P, Hotez PJ .Toxocariasis: An occult cause of childhood neuropsychological deficits and asthma? Seminars in Pediatric Infectious Diseases 11(4): 257-260.

17. Federico MJ, Liu AH. Overcoming childhood asthma disparities of the inner-city poor. PediatrClin North Am. 2003;50(3):655-75. vii.

18. Lenoir MA. Asthma in inner cities. J Natl Med Assoc. 1999;91(8 Suppl):1S-8.

19. Smith DE, Ashiabi GS. Poverty and child outcomes: A focus on jamaican youth. Adolescence. 2007;42(168):837-58.

20. Bergen DC. Effects of poverty on cognitive function: A hidden neurologic epidemic. Neurology. 2008;71(6):447-51. doi:10.1212/ 01.wnl. 0000324420.03960.36.

21. Jones JL, Kruszon-Moran D, Won K, Wilson M, Schantz PM. Toxoplasma gondii and toxocara spp. co-infection. Am J Trop Med Hyg. 2008;78(1):35-9.

22. Good B. Ocular toxocariasis in schoolchildren. Clin Infect Dis. 2004;39:173-8.

23. Hotez PJ, Wilkins PP. Toxocariasis: America's Most Common Neglected Infection of Poverty and a Helminthiasis of Global Importance? PLoSNegl Trop Dis 3(3): doi:10.1371/journal.pntd. 0000400

24. Ocular Toxocariais-United States, 2009-2010. MMWR. 2011;60(22):734-6.

25. Maetz HM, Kleinstein RN, Federico D, Wayne J. Estimated prevalence of ocular toxoplasmosis and toxocariasis in Alabama. J Infect Dis. 1987;156:414.

26. Hotez PJ. Forgotten People and Forgotten Diseases. American Society of Microbiology Press, 2008.

27. Embil JA, Tanner CE, Pereira LH, Staudt M, Morrison EG, Gualazzi D. Seroepidemiologic survey of Toxocaracanis infection in urban and rural children. Public Health. 1988;102(2):129-33.

28. Ghadirian E, Viens P, Strykowski H, Dubreuil F. Epidemiology of toxocariasis in the Montreal area. Prevalence of Toxocara and other helminth ova in dogs and soil. Canadian Journal of Public Health. 1976;67(6):495-8.

29. Hotez PJ, Bottazzi ME, Franco-Paredes C, Ault SK, Periago MR. The Neglected Tropical Diseases of Latin America and the Caribbean: A Review of Disease Burden and Distribution and a Roadmap for Control and Elimination. PLoSNegl Trop Dis 2(9): e300. doi:10.1371/journal.pntd.0000300.

30. Martínez I, Gutiérrez M, Fernández AM, Perez MJ, Vázquez O, García Y. Toxocaracanis en unapoblación escolar. Rev MexPatolClin. 1997;44(2):85-9.

31. Tinoco-Gracia L, Barreras-Serrano A, López-Valencia G, TamayoSosa A, Quiroz-Romero H, Melgarejo T. Seroprevalence of larva migrans of Toxocaracanis and evaluation of associated risk factors among children in a Mexico-United States border region. Intern J Appl Res Vet Med. 2008;6(2):130-6.

32. Romero C, Ponce M, Mendoza GD, Bustamante P, Arteaga SY, Ramírez N. Prevalence and Risk Factors Associated with 
Toxocaracanis Infection in Children. The Scientific World Journal 2013 pag $1-4$.

33. Romero C, Ponce M, Mendoza GD, Bustamante P, Arteaga SY, Ramírez N. Prevalence and Risk Factors Associated with Toxocaracanis Infection in Children. The Scientific World Journal 2013 pag 1-4. doi. 10.1155/2013/572089.

34. EncuestaNacional de Salud y Nutrición 2012. Estado de nutrición, Anemia, Seguridadalimentaria en la población Mexicana. InstitutoNacional de SaludPública.

35. González-de Cossío T, Rivera JA, González-Castell D, UnarMunguía M, Monterrubio EA. Child malnutrition in Mexico in the last two decades: prevalence using the new WHO2006 growth standards. SaludPublicaMex. 2009;51 suppl 4: S494-506.

36. Alvarado-Esquivel C. Toxocariasis in Waste Pickers: A Case Control Seroprevalence Study. PLoS ONE. 2013;8(1):e54897. doi:10.1371/ journal.pone.0054897.

37. Monge E, Barrantes M. Prevalencia de huevecillos de Toxocaraspp en los alrededores de la ciudad de San José. Rev Cost Cienc Méd. 1986;7(4):339-42.

38. Fragoso RP, Monteiro MB, Lemos EM, Pereira FE. Anti-Toxocara antibodies detected in children attending elementary school in Vitoria, State of Espírito Santo, Brazil: prevalence and associated factors. Rev Soc Bras Med Trop. 2011;44(4):461-6.

39. Campos Júnior D, Elefant GR, Silva EO DMe, Gandolfi L, Jacob $\mathrm{CM}$, Tofeti A, et al. Frequency of seropositivity to Toxocaracanis in children of different socioeconomic strata. Rev Soc Bras Med Trop. 2003;36(4):509-13

40. Teixeira CR, Chieffi PP, Lescano SA, de Melo Silva EO, Fux B, Cury MC. Frequency and risk factors for toxocariasis in children from a pediatric outpatient center in southeastern Brazil. Rev Inst Med Trop Sao Paulo. 2006;48(5):5.

41. AnarumaFilho F, Chieffi PP, Correa CR, Camargo ED, Silveira EP, Aranha JJ. Human toxocariasis: a seroepidemiological survey in the municipality of Campinas (SP), Brazil. Rev Inst Med Trop Sao Paulo. 2002;44(6).

42. Coelho LM, Silva MV, Dini CY, GiaconNeto AA, Novo NF, Silveira EP. Human toxocariasis: a seroepidemiological survey in schoolchildren of Sorocaba. Brazil MemInst Oswaldo Cruz. 2004 Oct;99(6):553-7.

43. Rubinsky-Elefant G, da Silva-Nunes M, Malafronte RS, Muniz PT, Ferreira MU. Human toxocariasis in rural Brazilian Amazonia: seroprevalence, risk factors, and spatial distribution. Am J Trop Med Hyg. 2008 Jul;79(1):93-8.

44. Alderete JM, Jacob CM, Pastorino AC, Elefant GR, Castro AP, Fomin AB. Prevalence of Toxocara infection in schoolchildren from the Butantã region, São Paulo. Brazil MemInst Oswaldo Cruz. 2003 Jul;98(5):593-7.

45. De Andrade Lima Coêlho R, De Carvalho Jr LB, Perez EP, Araki $\mathrm{K}$, Takeuchi T, Ito A, et al. Prevalence of toxocariasis in northeastern Brazil based on serology using recombinant Toxocaracanis antigen. Am J Trop Med Hyg. 2005;72:103-7.

46. Santarém VA, Leli FN, Rubinsky-Elefant G, Giuffrida R. Protective and risk factors for toxocariasis in children from two different social classes of Brazil. Rev InstMed Trop Sao Paulo. 2011;53:66-72.
47. Alonso JM, López MA, Bojanich MVI, Marull J. Infección por Toxocara canis en población adulta sana de un área subtropical de Argentina. Parasitología Latino americana. 2004;59:61-4.

48. Kuruc J, Zunino MG, De Francesco, V et al. Uso de las plazas de la ciudad de Buenos Aires porhumanos y porperros en relación con la transmisión de helmintospor la materia fecal canina. $1^{\circ}$ CongresoLatinoamericano de Zoonosis 1995, (Buenos Aires) Abstract Z-13.

49. Lopez MA, Alonso JM, Bonjanich MV, Chamorro MC, Falivene G. Aspectos inmunológicos de la infección infantil por Toxocara canis en el área del Gran Resistencia.. Instituto de Medicina Regional - UNNE. Resumen: M-017, 2003.

50. Alonso JM, Stein M, Chamorro MC, Bolanich MV. Contamination of soils with eggs of Toxocara in a subtropical city in Argentina. J Helminthol. 2001;75:1-4.

51. Fillaux J, Santillan G, Magnaval JF, Jensen O, Larrieu E, Sobrino CD. Epidemiologu of Toxocariasis in a steppe enviroment: The Patagonia Study. Am. J. Trop. Med. Hyg., 76(6), 2007.

52. Radman NE, Archelli SM, Fonrouge RD, Guardis MV, Linzitto OR. Human Toxocariasis. Its Seroprevalence in the City of La Plata. MemInst Oswaldo Cruz, Rio de Janeiro, Vol. 95(3): 281-285.

53. Alonso J, Bojanich M, Chamorro M, Gorodner J. Toxocara seroprevalence in children from a subtropical city in Argentina. Rev Inst Med Trop Sao Paulo. 2000;42:235-7.

54. Chiodo P, Basualdo J, Ciarmela L, Pezzani B, Apezteguia M, Minivielle M. Related factors to human toxocariasis in a rural community of Argentina. MemInst Oswaldo Cruz, Rio de Janeiro. June 2006;101(4):397-400.

55. Espinoza Y, Huapaya $\mathrm{P}$, Roldan $\mathrm{H}$, et al. Clinical and serological evidence of Toxocara infection in school children from Morrope district, Lambayeque, Peru. Rev Inst Med Trop Sao Paulo. 2008;50: $101-5$.

56. Lescano SA, Chieffi PP, Peres BA, de Mello EO, Velarde CN, Salinas AA. Soil contamination and human infection by Toxocara $s p$. in the urban area of Lima, Peru. MemInst Oswaldo Cruz. 1998;93:733-4.

57. Beaver PC, Snyder CH, Carrera GM, Dent JH, Lafferty JW. Chronic eosinophilia due to visceral larva migrans, report of three cases. Pediatrics. 1952;9:7-19.

58. Latuff H, Cardozo R. El síndrome de larva visceral migratoria. Arch VenezPuerPediat. 1968;31:157.

59. Pifano F, Orihuela R, Delgado O, et al. Latoxocariasishumana en Venezuela, especialmente en el Valle de Caracas. Gac Med Caracas. 1988;96:31-42.

60. Lynch NR, Eddy K, Hodgen AN, Lopez RI, Turner KJ. Seroprevalence of Toxocaracanis infection in tropical Venezuela. Trans R Soc Trop Med Hyg. 1988;82:275-81.

61. Hotez PJ, Dumonteil E, Heffernan MJ, Bottazzi ME. Innovation for the 'bottom 100 million': eliminating neglected tropical diseases in the Americas. AdvExp Med Biol. 2013;764:1-12. An important reflexion about the toxocariasis and other neglected tropical diseases in the Americas.

62.• Macpherson $\mathrm{CN}$. The epidemiology and public health importance of toxocariasis: a zoonosis of global importance. Int J Parasitol. 2013;43:999-1008. Very recent mini-review discussing the relevance of toxocariasis as one of the most important global zoonosis. 